DOI: $10.47456 / k r k r . v 2 i 4.32040$

\title{
Produção escrita na educação do campo: experiências, desafios e possibilidades
}

Written production in the field education: experiences, challenges and possibilities

Roseli Gonoring Hehr Erineu Foerste

Resumo: Este artigo apresenta a investigação de práticas escolares de produção escrita em uma turma dos Anos Finais do Ensino Fundamental de uma escola campesina do município de Domingos Martins, Estado do Espírito Santo, Brasil. A partir do questionamento de como são as práticas escolares de produção escrita em uma escola do campo, e em diálogo com os estudos teóricos de Freire (2013) e Arroyo (2007) explanamos as situações de opressão na Educação do Campo a partir do currículo; Bakhtin $(2010,2013)$ e Geraldi (2013) conduziram a análise das práticas escolares de produção escrita; Brandão (2009) contribuiu para pensarmos cultura e Candau (2012) fundamentou as reflexões sobre interculturalidade, necessárias ao pensarmos a cultura escolar e a cultura da escola, numa perspectiva de educação que considera a diversidade cultural, histórica e social dos sujeitos. Pesquisa fundamentada na abordagem qualitativa, conforme preceitua Ludke e André (2006). O Estudo de Caso favoreceu a nossa participação no ambiente escolar, para registro e análise de práticas escolares voltadas à linguagem escrita. Os resultados da pesquisa demonstram que a escola do campo tem proporcionado práticas escolares diferenciadas, ligadas à realidade dos educandos. No entanto, as produções têm priorizado os textos pragmáticos e referenciais, em detrimento de produções de textos literários. A formação continuada de educadores tem contribuído para a reflexão e mudança nas práticas escolares de produção escrita.

Palavras-chave: Educação do Campo; Produção escrita significativa, currículo.

Abstract: This article presents the investigation of school practices of written production in a class of the Final Years of Elementary Education of a peasant school in the city of Domingos Martins, State of Espírito Santo, Brazil. From the questioning of the school practices of written production in a rural school, and in dialogue with the theoretical studies of Freire (2013) and Arroyo (2007), we explain the situations of oppression in Rural Education from the curriculum; Bakhtin $(2010,2013)$ and Geraldi (2013) conducted the analysis of school practices of written production; Brandão (2009) contributed to thinking about culture and Candau (2012) based the reflections on interculturality, necessary when thinking about school culture and school culture, in an education perspective that considers the cultural, historical and social diversity of the subjects. Research based on the qualitative approach, as stated by Ludke and André (2006). The Case Study favored our participation in the school environment, for recording and analyzing school practices focused on written language. The results of the research demonstrate that the school in the countryside has provided differentiated school practices, linked to the reality of the students. However, productions have prioritized pragmatic and referential texts, to the detriment of literary texts. The continuing education of educators has contributed to the reflection and change in school practices of written production.

Keywords: Field education; significant written production, curriculum. 


\section{Introdução}

Este artigo surge da inquietação de uma professora pesquisadora sobre as práticas escolares de produção escrita instituídas na escola e da esperança de que caminhos diferentes e possíveis possam ser trilhados. A linguagem é o meio pelo qual nos constituímos como sujeitos, num processo que implica interação, trocas, conflitos com nossos pares. É nesse contexto singular que a fala, a escrita, o discurso são elaborados e podem demonstrar toda complexidade desse processo, que nos traduz como seres únicos e coletivos.

Por meio da leitura e interações sociais a produção escrita toma forma, se faz e se refaz à medida que ampliamos nossas leituras e vivências, assim expressamos nossos pensamentos, ideias, argumentamos, ou seja, exercemos o direito de dizer nossa palavra por meio da escrita, sendo esta uma das formas de emancipação dos sujeitos. Por isso, este estudo assume um papel emancipador, ao reconhecermos que a escola é a principal responsável pela aquisição da leitura e apropriação da palavra escrita, e problematizarmos: Como são as práticas de produção escrita em uma escola do campo?

Para Bakhtin (2010b), na relação criadora com a língua, não existem palavras sem voz; em cada palavra há vozes, às vezes distantes, anônimas, impessoais e também vozes próximas. Assim, a língua mostra-se como possibilidade de comunicação que, a partir da interação com os interlocutores, constitui e fundamenta a linguagem.

Partindo desse princípio, fundamentada na perspectiva sócio-histórica em que Vigostki (1996) nos faz refletir sobre a importância das vivências, dos aspectos sociais, históricos e culturais na formação dos sujeitos é que nos propusemos a pesquisar as práticas escolares de produção escrita. Esta investigação nos permitiu analisar as referidas práticas, observando o contexto campesino onde a escola encontra-se inserida, as produções escritas marcadas/atravessadas pela cultura escolar e a cultura da escola e a importância da formação continuada de professores ofertada pelo município para reflexão sobre as práticas pedagógicas. 


\section{Do direito à educação à produção escrita significativa e contextualizada}

Recorrer aos documentos oficiais torna-se uma prática necessária quando discutimos educação, uma vez que muitas justificativas para o que se faz ou deixa de ser feito apoiam-se na legislação vigente que rege a educação brasileira. Também subsidiar o estudo com a contribuição de pesquisadores e estudiosos, por meio de produções acadêmicas colaboram para a problematização do assunto em pauta.

Nos Parâmetros Curriculares Nacionais de Língua Portuguesa (2001), documento oficial que orientou muitas redes e sistemas de ensino, destacamos os objetivos que versam sobre a produção escrita, assim evidenciados

Utilizar a linguagem na escuta e produção de textos orais e na leitura e produção de textos escritos de modo a atender a múltiplas demandas sociais, responder a diferentes propósitos comunicativos e expressivos, e considerar as diferentes condições de produção do discurso;

Utilizar a linguagem para estruturar a experiência e explicar a realidade, operando sobre as representações construídas em várias áreas do conhecimento;

Conhecer e valorizar as diferentes variedades do português, procurando combater o preconceito lingüístico; (BRASIL, 2001)

A LDB, Lei no 9394/96 diz, em eu artigo 26, que

Art. 26 Os currículos do ensino fundamental e médio devem ter uma base nacional comum a ser complementada, em cada sistema de ensino e estabelecimento escolar, uma parte diversificada, exigida pelas características regionais e locais da sociedade, da cultura, da economia e da clientela. (BRASIL, 1996)

E especifica em seu artigo 28 a questão da educação do campo

Art. 28. Na oferta de educação básica para a população rural, os sistemas de ensino promoverão as adaptações necessárias à sua adequação às peculiaridades da vida rural e de cada região, especialmente:

I - conteúdos curriculares e metodologias apropriadas às reais necessidades e interesses dos alunos da zona rural ( BRASIL,1996)

Nesse sentido, as Diretrizes Operacionais para a Educação Básica nas Escolas do Campo em seu art. $2^{\circ}$, $\S$ único, afirmam que 
[...] a identidade da escola do campo é definida pela sua vinculação às questões inerentes a sua realidade, ancorando-se na temporalidade e saberes próprios dos estudantes, na memória coletiva que sinaliza futuros, na rede de ciência e tecnologia disponível na sociedade e nos movimentos sociais em defesa de projetos que associem as soluções exigidas por essas questões à qualidade social da vida coletiva no país. (BRASIL,2002).

A BNCC para a Educação Infantil e o Ensino Fundamental, homologada em dezembro de 2017, entre as competências específicas de linguagens para o ensino fundamental, apresenta

\begin{abstract}
Utilizar diferentes linguagens para defender pontos de vista que respeitam o outro e promovam os direitos humanos, a consciência socioambiental e o consumo responsável em âmbito local, regional e global, atuando criticamente frente a questões do mundo contemporâneo. (BRASIL, 2017, p.6)
\end{abstract}

Os trechos dos documentos mencionados evidenciam o direito do educando, nos mais diversos contextos, quanto à garantia de uma educação que considere seus interesses, sua cultura, seu modo de ser e lhes assegure a aprendizagem da linguagem escrita.

Para Brandão ( p. 717, 2009) cultura, em uma visão imaterial, apresentase na tessitura de sensações, saberes, sentidos, significados, sensibilidades e sociabilidades com que pessoas e grupos de pessoas atribuem socialmente palavras e idéias, visões e versões partilhadas ao que vivem, criam e fazem ao compartilharem universos simbólicos que elas criam e de que vivem. Essa visão nos faz refletir sobre a necessidade da escola conhecer os sujeitos estudantes que ali estão, ouvi-los e respeitá-los em seus saberes, contos, causos, crenças fortalecendo o grupo constituído, sua identidade, bem como da comunidade onde a escola se encontra.

Nesse sentido, no banco de dissertações e teses da CAPES, pesquisas como a de LOPES (2011), O capital cultural da criança na aprendizagem da linguagem escrita, em que analisa até que ponto o capital cultural das crianças interfere na aprendizagem da linguagem escrita, tendo como eixo norteador os sentidos produzidos sobre o processo de alfabetização pelos diferentes sujeitos, integrantes da prática pedagógica (professora, alunos e pais) de uma classe de primeiro ano de uma escola pública do município de Santo Antônio do Planalto 
- RS. Destaca-se a conclusão da pesquisadora que delega a escola, como historicamente responsável pela efetivação da aprendizagem da linguagem escrita, pontuando que se leve em consideração repensar suas práticas alfabetizadoras, integrando metodologicamente o capital cultural da criança no ensino da linguagem escrita e tendo como parceiros os sujeitos integrantes das diferentes configurações familiares existentes no meio social em que ela está inserida.

Geraldi (2010) afirma que a escola pode representar um espaço de libertação, mas também de dominação dependendo da mediação feita junto aos estudantes, dos textos disponibilizados para leitura e produção, ao nos proporcionar a seguinte reflexão

O ideal, do ponto de vista da estabilidade paradoxal que a escola assume - ela ao mesmo tempo se diz formando para o futuro, mas faz isso forçando para que o futuro seja a repetição do passado - seria afastar de vez o texto da sala de aula. Mas isto é impossível por uma razão mais ou menos óbvia: o processo de fixação de valores demanda o convívio com discursos materializados nos textos; os valores e as concepções circulam através dos textos e sem eles a escola não cumpriria uma de suas funções mais sofisticadas: a reprodução de valores com que compreender o mundo, os homens e suas ações. De um lado o texto traz o perigo da instabilidade; de outro lado, o texto é um lugar privilegiado para construir estabilidades sociais. Não há escapatória: no ensino de língua materna, o texto há de estar presente. (GERALDI, p.141, 2010)

A linguagem tem um poder incontestável e por isso

[...] é condição sine qua non na apreensão e formação de conceitos que permitem aos sujeitos compreender o mundo e nele agir; ela é ainda a mais usual forma de encontro, desencontro e confronto de posições porque é através dela que estas posições se tornam públicas. Por isso é crucial dar à linguagem o relevo que de fato tem : não se trata evidentemente de confinar a questão educacional, mas trata-se da necessidade de pensá-la a luz da linguagem. (GERALDI, 2010, p. 34)

Entendemos que considerar os aspectos sociais, culturais e históricos do educando pode contribuir não apenas para a permanência desses sujeitos no ambiente escolar, como também, permitir que se apropriem desse recurso para utilizarem em seus ambientes de interação: família, escola, igreja, comunidade e sociedade como um todo. 
Conforme afirma Bakhtin

$\mathrm{Na}$ realidade, toda palavra comporta duas faces. Ela é determinada tanto pelo fato de que procede de alguém, como pelo fato de que se dirige para alguém. Ela constitui justamente o produto da interação do locutor e do ouvinte. Toda palavra serve de expressão a um em relação ao outro. Através da palavra defino-me em relação ao outro, isto é, em última análise, em relação à coletividade. A palavra é uma espécie de ponte lançada entre mim e os outros. Se ela se apoia sobre mim numa extremidade, na outra apóia-se sobre o meu interlocutor. A palavra é o território comum do locutor e do interlocutor (BAKHTIN, 2011, p.117).

Uma prática desvinculada da realidade do educando incorre num trabalho com a palavra descompromissado com a função social da escrita, e como consequência, os educandos podem sentir-se desestimulados por não conseguirem perceber a necessidade, a importância, tampouco a aplicabilidade do que lhes é ensinado.

Freire nos fala de forma bem específica da leitura e da escrita no processo de alfabetização de adultos, no entanto, consideramos bem pertinente suas contribuições serem pensadas também para os educandos campesinos, quando destaca

O aprendizado da leitura e da escrita, por isso mesmo, não terá significado real se se faz através da repetição puramente mecânica de sílabas. Este aprendizado só é válido quando, simultaneamente com o domínio do mecanismo da formação vocabular, o educando vai percebendo o profundo sentido da linguagem. Quando vai percebendo a solidariedade que há entre a linguagem-pensamento e realidade, cuja transformação, ao exigir novas formas de compreensão, coloca também a necessidade de novas formas de expressão. (FREIRE, 1981, p.20)

Assim, a linguagem escrita produzida pelos educandos pode nos revelar muito do processo educativo, Bakhtin (2010, p.309) diz que

[...] por trás de cada texto está o sistema de linguagem. A esse sistema corresponde no texto tudo o que é repetido e reproduzido e tudo o que pode ser reproduzido e repetido, tudo que pode ser dado fora de tal texto (o dado). Concomitantemente, porém, cada texto (como enunciado) é algo individual, único e singular, e nisso reside todo o seu sentido (sua intenção em prol da qual ele foi criado). É aquilo que nele 
tem relação com a verdade, com a bondade, com a beleza, com a história.

Nas palavras do autor, fica evidente que a interferência, a fala, as opiniões e posicionamentos do educador, de acordo com o assunto ou temática abordada, certamente aparecerá no texto do educando, mas com a identidade do sujeito que o produz.

Silva (2002) pontua em seu livro Documentos de Identidade que para Althusser, a escola é compreendida como aparelho ideológico do Estado, que produz e dissemina a ideologia dominante através, principalmente, dos conteúdos. Bowles e Gintis dão ênfase à aprendizagem por meio da vivência e das relações sociais na escola que irão repercutir na formação de atitudes necessárias no mercado de trabalho capitalista. Bourdieu e Passeron desenvolvem o conceito de "reprodução" e "capital cultural", no qual a cultura dominante incorpora, introjeta e internaliza determinados valores dominantes através do currículo escolar.

A partir das contribuições de Silva (2002) podemos considerar que a escola sempre está a serviço de alguém, mas não necessariamente dos sujeitos que a procuram, busca atender a uma demanda do governo, dos empresários, da classe dominante, o que reforça a ideia de que o currículo, tampouco os conteúdos são pensados, no caso deste estudo, para atender interesses dos estudantes campesinos e de suas famílias.

Arroyo (2016) nos provoca a refletir sobre o conflito e as tensões vividos pelo professores ao afirmar que

Nesse novo contexto as tensões identitárias aumentaram. As condições de trabalho não melhoraram e as tentativas de ampliar a função docente incorporando papéis que os educandos demandam nas salas de aula são limitadas e estão sendo freadas pela retomada da condição de aulistas, treinadores de alunos para bons resultados em avaliações nacionais . Avaliações que agem como imperativos categóricos para retomar a função de aulistas, repassadores de conteúdos, treinadores de competências que garantam bons resultados dos alunos. O repensar e alargar nossas identidades profissionais passa por resistências, freios. Podemos entender tais resistências como disputas de conformação de identidades profissionais no território dos currículos. (Arroyo, 2013, p. 27) 
Arroyo ao falar das tensões presentes no cotidiano escolar nos instiga a pensar sobre a cultura escolar e a cultura da escola, uma vez que as tensões são causadas pelas imposições e regras que desconsideram a função docente, bem como, os anseios e necessidades reais dos estudantes.

Conforme Demenech (2016, p. 24), a cultura escolar tem suas regras, normas, ritos, ideais, crenças, hierarquias, valores, princípios de ordem e classificação, representações mentais e, assim, com linguagens, significados simbólicos ou reais mais ou menos evidentes, entre outros, que compõem a estrutura da escola, como, o conjunto dos conteúdos cognitivos e simbólicos que, selecionados, organizados, 'normatizados', 'rotinizados', sob o efeito dos imperativos de didatização, constituem habitualmente o objeto de uma transmissão deliberada no contexto das escolas.

Em contraponto Demenech (2016, p.26) afirma que as pessoas vivem de forma peculiar essa cultura, ressignificam e dão conta das tensões e contradições, reorganizando a vida escolar, suas ações e constituindo assim a cultura da escola. Entendemos que este movimento é tão essencial para que o tempoespaço escolar seja acolhedor, entenda o estudante em seus aspectos sociais, históricos e culturais, assim também respeitando a função docente daquele que está no lócus da escola, vive suas dificuldades e enxerga as possibilidades e necessidades dos sujeitos que constituem a comunidade escolar.

Nesse tensionamento, pensar a questão intercultural, no âmbito escolar, torna-se urgente, quando nos remetemos aos materiais didáticos disponibilizados para as escolas do campo, que, por vezes, apresentam temáticas, textos e proposições escritas que ignoram a realidade e necessidade campesina; quando entendemos que a formação inicial dos professores apresenta o contexto das escolas campesinas, suas especificidades e necessidades de forma muito tímida e superficial; quando às situações de discriminação e exclusão por que passam estudantes que trazem consigo determinadas marcas identitárias no comportamento, na forma de falar ou de vestir os levam a desistir dos estudos.

A educação numa perspectiva intercultural pressupõe 
[...] oferecer elementos que colaborem para a construção de práticas pedagógicas comprometidas com a equidade, a democracia e a afirmação do direito à educação e a aprendizagem de toda criança, de todo adolescente, de toda pessoa humana. Parte da tese de que superar as situações acima mencionadas exige um processo continuo de desconstrução de aspectos fortemente configuradores da cultura escolar vigente e a promoção de uma educação em direitos humanos na perspectiva intercultural. (CANDAU, 2012, p.247)

Assim, uma educação intercultural passa pela compreensão, por parte de gestores e educadores, de que o sistema escolar e a cultura escolar podem ser repensados, considerando os educandos como sujeitos de direitos, vistos na condição de pessoa humana, que têm sua identidade, cultura e histórias. $O$ respeito e a valorização desses aspectos implicam em práticas pedagógicas diferenciadas, que possibilitam aos educandos se apropriar dos conhecimentos social e historicamente reconhecidos, como também, registrar seus saberes e idéias que se tornam importantes produções de memórias e conhecimentos desses sujeitos.

\section{$O$ contexto da escola pesquisada}

Ao optar pela escola em que realizei a pesquisa considerei alguns aspectos, como o trabalho diferenciado que tinha conhecimento que era realizado, a proximidade da escola da Sede do município a cerca de $15 \mathrm{~km}$, onde resido, a realidade campesina dos estudantes que ali estudam e os resultados obtidos pela escola na Prova Brasil que entre outros critérios gera a nota do IDEB.

A iniciativa para ter aulas na localidade de São Miguel surge na década de 50, do desejo de algumas pessoas que queriam que seus filhos tivessem acesso à educação, para que eles aprendessem a ler e escrever, e assim, os pais pagavam a pessoa para ministrar as aulas.

Na mesma década, por volta de 1958, o poder público assumiu o ensino com a construção da Escola Singular de São Miguel, construída próximo à Igreja Católica da comunidade. Nesse período, era uma escola unidocente, em que um professor lecionava para todas as turmas juntas, no caso, os anos iniciais do EF. 
Devido ao aumento da demanda de alunos, passou a atender da educação infantil aos anos finais do EF, em salas seriadas.

Os pais,em sua maioria, são pequenos agricultores e a economia da comunidade está baseada na produção agrícola em que se destacam produtos como o café, a banana da terra e a mexerica Pocan, que são comercializados no próprio município e na Ceasa em Cariacica. Na comunidade, há a presença de uma associação denominada APROSMIC- Associação dos Produtores Rurais de São Miguel e Região.

Os sujeitos desta pesquisa são os educadores e educandos da EMEF Eugênio Pinto Sant'Anna, sendo quatro participantes por parte dos educadores e vinte e cinco estudantes da $7^{a}$ série do EF.

Muitos estudantes são descendentes de alemães e pomeranos, filhos de pequenos agricultores e meeiros da própria comunidade. Registra- se também, nessa turma, a presença de estudantes oriundos do município de Santa Leopoldina. Devido à atividade das famílias na lavoura e cultivo da terra, temos relatos de que muitos educandos/filhos auxiliam os pais nas atividades agrícolas no horário em que não estão na escola.

Priorizamos, na pesquisa, a observação das aulas de Língua Portuguesa, Matemática, História, Geografia e Ciências, considerando a frequência das aulas e as possibilidades de produção escrita que essas disciplinas permitem. Os profissionais que participaram da pesquisa têm curso de licenciatura no componente curricular em que atuam, sendo exceção a professora de matemática que, além de ministrar a referida disciplina para a qual é habilitada, também assumiu o componente Geografia para o qual não possui habilitação. Apesar da proximidade com a Sede do município, a escola não conseguiu completar o quadro com todos os profissionais habilitados, o que ocorre com frequência nas escolas do campo não só em Domingos Martins, mas num contexto estadual e nacional.

\section{Na escola: experiências, desafios e possibilidades}

Durante alguns meses acompanhei inúmeras atividades realizadas pela escola. Destaco a Blitz ecológica que aconteceu no dia da árvore. Na ocasião 
foram organizadas quatro espaços pelos quais os estudantes passavam por turma num sistema de rodízio. Um grupo ficou com um palestrante, conhecido por guarda Bello que falou sobre a necessidade e importância da preservação das matas, outro grupo com a Sra Alessandra do Instituto Kautsky que tratou sobre a reciclagem do lixo, um terceiro grupo ficou na estrada parando carros com o apoio da polícia militar para entregar uma muda de Araçaúna com um texto informativo e um quarto grupo com o professor de Educação Física que oportunizou um momento de lazer.

Este dia foi muito intenso para os estudantes que demonstraram interesse pelas situações propostas e participaram ativamente dos momentos oportunizados pela escola.

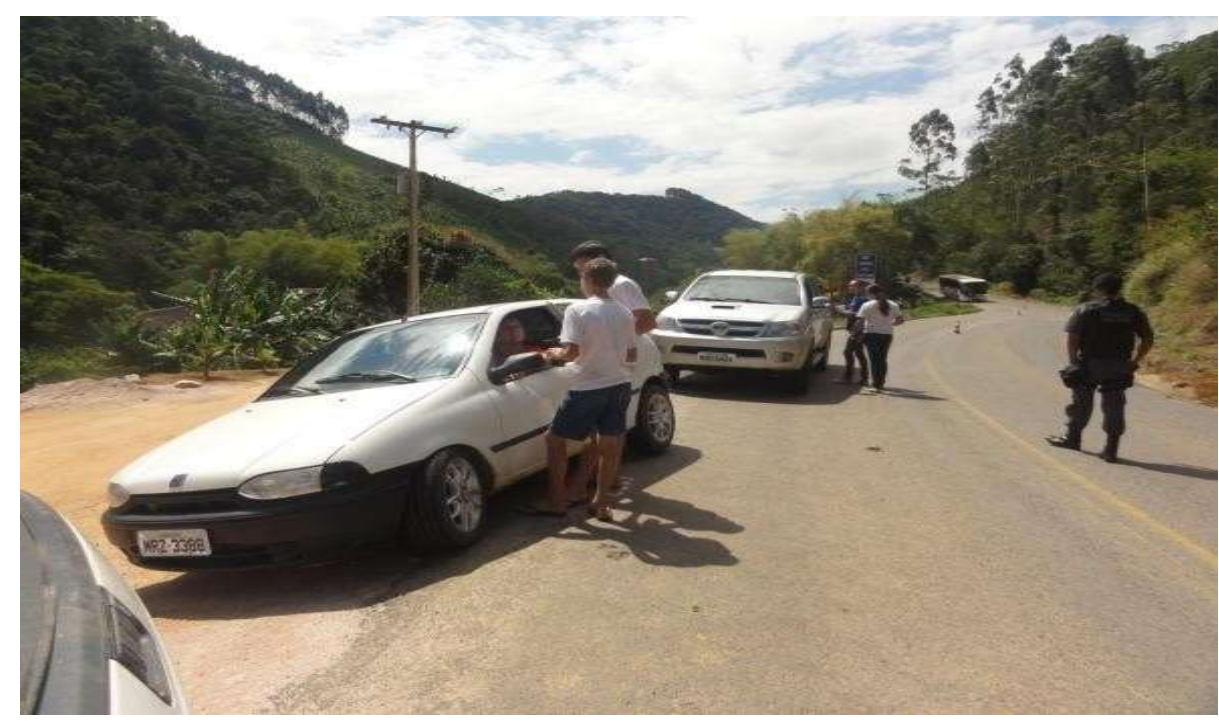

Fonte: Arquivo da autora

Pit Stop da Blitz Ecológica 
No dia seguinte, voltamos à escola na expectativa de como seriam as aulas diante do que havíamos vivenciado no dia anterior. Observamos que a educadora de matemática propôs a produção de um gráfico que representasse a quantidade de veículos que passaram pelo Pit Stop, de acordo com o tipo dos veículos: carro de passeio, carro pequeno com carroceria, caminhão e moto. Como apresentamos a seguir:

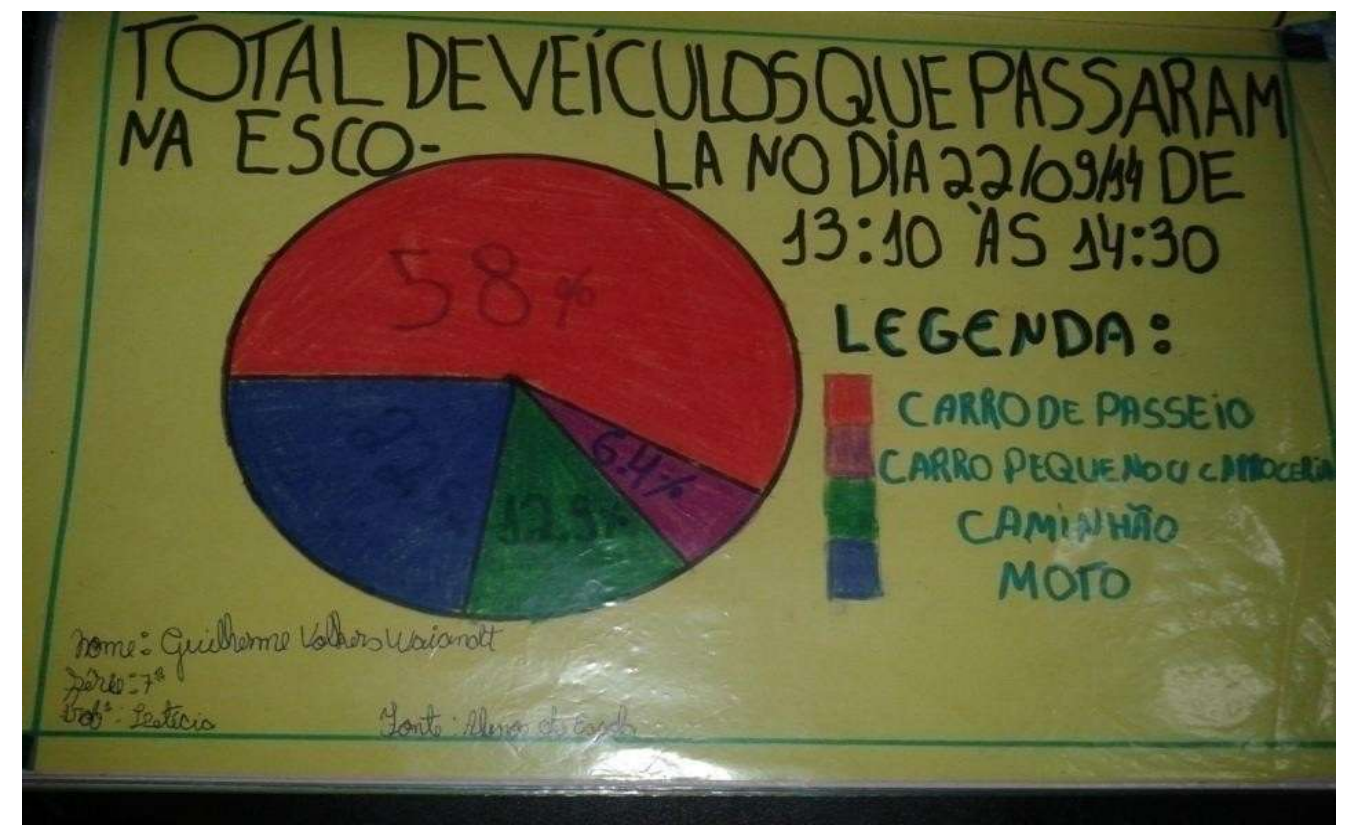

Fonte: Arquivo da autora

Gráfico Pit Stop da Blitz Ecológica

As demais disciplinas não contemplaram, na $7^{\text {a }}$ série, em seus planejamentos, aulas, leituras, debates e produções relacionadas às atividades que foram realizadas com os educandos no dia 21/09. Entendemos que a escola oportunizou momentos interessantes que motivaram e envolveram os estudantes, com temáticas relevantes como lixo, preservação do meio ambiente, no entanto, nos deparamos com uma ruptura marcante de um dia para o outro.

Com exceção da educadora de matemática, as outras propostas estiveram pautadas em atividades a serem cumpridas no livro didático, à explicação de conteúdos específicos das disciplinas que não estavam relacionadas às intensas ações do dia anterior. Não podemos negar que nossa expectativa quanto ao incentivo de produções textuais, tendo como referência os 
assuntos e momentos promovidos pela escola era grande, mas não se concretizou.

Esse movimento de ruptura nos reporta à fala das educadoras no grupo focal, quando manifestaram que os educandos gostam das atividades diferenciadas, são participativos, mas que por outro lado, elas se preocupam se irão conseguir cumprir o currículo proposto para a turma naquele ano, com isso não conseguem desenvolver os projetos como gostariam, por se sentirem responsáveis em repassar todo o conteúdo definido para aquela turma.

Uma coisa que me deixa inquieta e poderia até ser levado mais a frente em relação à formação de professores, é ainda a questão do livro didático, mesmo pra mim, eu fico preocupada, no final do ano letivo, eu não dei conta daqueles conteúdos, a gente fica preocupado e dá mais valor ao livro didático do que o projeto e olha como faz diferença para o aluno. Agora você vai lá na sala da $7^{a}$ série e pergunta a eles, o último trabalho foi sistema de equação e do projeto Indústrias Caseiras, qual eles aprenderam mais? Se eu der uma questão de Sistema de Equação, talvez $10 \%$ da sala vai saber fazer e aí, onde que eles vão usar sistema de equação? Só quem for um professor de matemática, ou se tornar um engenheiro. (Professora $A$, disciplina de Matemática)

Essa passagem vívida na escola evidencia a força da cultura escolar em determinar, em muitos momentos, as práticas dos professores, especialmente neste estudo no que se refere a propor produções textuais que poderiam retratar momentos cheios de vida, histórias e conhecimento. A preocupação com o currículo a ser cumprido, o conteúdo a ser dado, por vezes inviabiliza a riqueza e o potencial criador de professores e estudantes.

Geraldi (2010, p.54), ao citar Foucault (1970), admite ser a disciplina um princípio de controle da produção do discurso, uma vez que [...] fixa os limites pelo jogo de uma identidade que tem a forma de uma reatualização permanente das regras [...], [...] aquilo que é requerido para a construção de novos enunciados $[\ldots]$ encontramos

O sentimento expresso pela educadora de que, mesmo ciente de que os educandos se interessam e produzem mais sentidos em seus estudos quando relacionados aos projetos que a escola propõe, sente-se pressionada e responsável pelo cumprimento dos conteúdos de sua disciplina, do livro didático, 
mesmo acreditando que sejam dispensáveis aos educandos. Apesar disso, no caso da atividade da Blitz Ecológica, não deixou de propor a produção de um texto gráfico aos estudantes, o que não ocorreu nas demais disciplinas, em que os conteúdos curriculares foram retomados no dia seguinte.

\section{Possibilidades de produção escrita - Projeto Integrando os Saberes}

Durante o período em que acompanhamos as aulas da $7^{\mathrm{a}}$ série, chamounos atenção o projeto Integrando os Saberes, atividade que a escola realiza desde 2009, em que, a partir de temas geradores, são propostas leituras, produções textuais, visitas pedagógicas, entrevistas e palestras, entre outras atividades. No caso da $7^{a}$ série, as temáticas que orientaram as atividades foram no $1^{\circ}$ trimestre - Saúde e Bem Estar (saúde Bucal); no $2^{\circ}$ trimestre - Criações e no $3^{\circ}$ trimestre- Indústrias Caseiras. As temáticas são escolhidas em reunião dos educadores, pedagoga e diretora e buscam, em suas escolhas, aproximação com a realidade dos educandos, mas que também possam dialogar com os conteúdos que são trabalhados durante o ano. Como na disciplina de Ciências da $7^{\mathrm{a}}$ série, um dos conteúdos para o ano é Corpo Humano, no Projeto garantiuse a temática Saúde e BemEstar.

Sobre os temas geradores, de acordo com Freire (p.121, 2013)

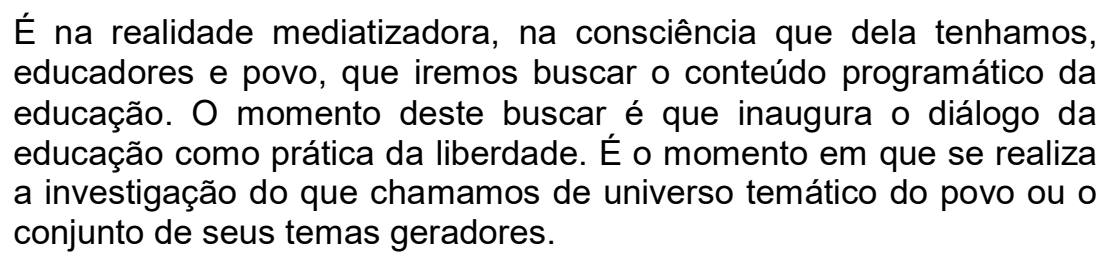

Para Freire (2013), a busca pela temática mostra-se complexa e pode ser até ingênua, pois os temas não podem ser encarados como se fossem coisas, fora do homem,-[...] Os temas, em verdade, existem nos homens, em suas relações como mundo, referidos a fatos concretos.[...]ll (FREIRE, 2013, p.137). Desse modo, o que poderia parecer algo simples e fácil de se fazer, escolher os temas, torna-se um ato que exige reflexão, diálogo e atenção às demandas dos educandos e da comunidade escolar.

E assim, consciente ou não dessa responsabilidade, em cada trimestre um professor assume uma temática com a turma, e os demais professores 
também se envolvem, por isso o projeto é denominado Integrando os Saberes, pois ocorre num movimento de integração das disciplinas. $\mathrm{Na} 7^{\mathrm{a}}$ série, a professora de Ciências ficou responsável pela temática-Saúde e Bem Estar, a professora de Matemática assumiu o tema Criações e a professora de História orientou a temática Indústrias Caseiras.

Essa proposta de trabalho assemelha-se com o Caderno da Realidade, adotado pelas Escolas Famílias Agrícolas - EFAs, que foram fundadas pelo MEPES (Movimento de Educação Promocional do Espírito Santo), e deram origem à Pedagogia da Alternância. Em Domingos Martins, há uma escola Família Agrícola localizada na comunidade de São Bento do Chapéu.

Conforme relatado pelos educandos no grupo focal, as produções textuais propostas pelo projeto, por terem aproximação com suas vivências e serem fundamentadas em outras ações, além de leituras, contribuem para a fluência de suas produções.

A gente primeiro faz é... estuda sobre aquele tema, pesquisa sobre aquele tema, faz visita, alguma coisa assim e aí a gente já sabe, tem alguma vantagem, já tem o conhecimento para escrever. (Aluno A)

Igual na sexta-feira a gente fez uma visita lá, fomos na Kebis, na Delícias Caseiras e na Hortaliças Klein em Campinho. Nós vamos ter que fazer um relatório, nós gravamos a entrevista com o dono da empresa e aí fica mais fácil para fazer o texto.ll (Aluno B)

A fala dos educandos vai ao encontro do pensamento de Geraldi (2010), ao evidenciar que o texto não pode ser considerado simplesmente uma produção técnica que é norteada por regras, mas se constrói num contexto que sofre interferências e influências desde a interlocução com o educador que pode ampliar-se a outros sujeitos participantes desse processo construtivo, como também do que se propõe como temática de produção.

A pasta em que são organizados os textos do Projeto Integrando Saberes apresenta um número significativo de produções escritas pelos educandos e, ao manusearmos este material tão repleto de textos, observamos a predominância de produção de relatórios. Geraldi (2010) ressalta que a escola tem priorizado, em suas atividades, a escolha por textos pragmáticos sustentados pelo projeto 
de cientificidade das ciências humanas, em prejuízo à literatura, à poesia. A coletânea de produções textuais observadas coadunam com as palavras de Geraldi (2010); dentre uma gama de textos escritos há a prevalência de produções de relatórios narrativos de visitas de estudo, de palestras e entrevistas.

Entendemos que o Projeto Integrando os Saberes conforme Foerste (2005) pretende atender aos interesses dos educandos de forma significativa, o que vem a ser uma necessidade para a qualidade da educação básica, afirma que

[...] as áreas do conhecimento do currículo da escola básica deviam se organizar para pensar problemas de cada disciplina e a construção coletiva de alternativas para dinamizar o cotidiano escolar, resgatando a qualidade do ensino da educação básica. (FOERSTE, 2005,p.23)

Ao assumirem coletivamente a responsabilidade pelo projeto, e consequentemente pelas ações envolvidas nessa proposta de trabalho, as educadoras buscam ressignificar as práticas da escola, principalmente no que se refere à produção escrita.

\section{A formação continuada em educação do campo e suas contribuições}

A formação de educadores ofertada pela Secretaria Municipal de Educação de Domingos Martins em parceria com a UFES colocou como diretriz dos estudos a Educação do Campo. Neste contexto, interessou-nos pesquisar junto às educadoras se a formação tem interferido em sua prática cotidiana.

De acordo com Candau (1997), ao analisar as políticas de formação continuada no Brasil, evidencia que grande parte dos projetos realizados atendem a uma perspectiva clássica, voltada para a "reciclagem" e "capacitação" de educadores, que em sua essência propõe a atualização das informações e conceitos recebidos na formação inicial. Assim

A formação continuada não pode ser concebida como um processo de acumulação de cursos, palestras seminários, etc. de conhecimentos ou técnicas mas sim como um trabalho de reflexibilidade crítica sobre a prática de reconstrução 
permanente de uma identidade pessoal e profissional, em interação mútua. (CANDAU, 1997, p.64)

Em análise ao histórico da formação continuada de educadores do município de Domingos Martins nos últimos anos, de 2009 a 2014, não entendemos ser esse o posicionamento da Secretaria Municipal de Educação do município, pois diferente do que nos apresenta a autora, as formações, de acordo com a Coordenadora do Centro de Pesquisa e Formação do município de Domingos Martins, tem objetivado proporcionar aos educadores reflexões sobre sua prática, considerando os sujeitos, suas realidades, problematizando as temáticas estudadas partindo da teoria e relacionando-as com a prática cotidiana, que resultaram em registros como artigos, baners entre outros e também na mudança das práticas escolares.

Perguntamos assim, as educadoras da EMEF Eugênio Pinto Sant'Anna" se a formação em Educação do Campo contribui para a atuação delas nos Anos Finais do EF, e obtivemos as seguintes respostas:

Sim, porque podemos trabalhar mais o dia a dia dos alunos. Ensiná-los dentro de sua realidade. Isso faz com que o aprendizado seja mais significativo. (Educadora A)

Penso que contribui, pois trabalho numa escola do campo que possui projetos educacionais voltados para a Educação do Campo. Além disso, a Educação do Campo é uma área muito rica e tem aperfeiçoado o meu desempenho como professora. (Educadora B)

Sim, foi a partir da formação que consegui compreender melhor meus alunos. (Educadora $\mathrm{C}$ )

Sim, vários são os fatores que contribuem para o desenvolvimento do meu trabalho educacional. Dentre eles destaco a troca de experiência entre colegas e instituições que participam junto na formação (Guaçu Virá) e despertam em mim a vontade de fazer diferente e de "testar" de certa forma experiências exitosas apresentadas por pessoas envolvidas no processo educacional. Destaco também o estudo individual e coletivo da teoria apresentada a cada ano, que possibilita entender a prática que nos cerca e apesar de ambos teoria e prática parecer tão distante é com o real envolvimento que é possível perceber e refletir a teoria no desenrolar de uma atividade prática onde todos os alunos participam e relatam suas experiências a partir da atividade desenvolvida. Desta maneira é possível questionar em algum momento a teoria e ou articular melhor a prática. (Educadora D)

As respostas das educadoras demonstram que a formação tem levadoas a compreender melhor a realidade dos seus educandos, uma vez que como já mencionado, apenas uma educadora é da comunidade, o que nos leva a 
entender que há um certo desconhecimento sobre a cultura, o modo de ser e de viver das pessoas, esteriótipos, no caso desta pesquisa, do campo. O que toma mais força, ao relacionarmos com o depoimento da educadora de Língua Portuguesa, ao nos relatar que em sua formação inicial não se falou em Educação do Campo, e que também na segunda graduação em Pedagogia a temática não foi contemplada. Tal relato reforça a ideia de negação dos povos do campo em sua mais ampla diversidade e nos mostra que a necessidade de se abrir espaço na academia desde a formação inicial para este assunto tornase urgente.

Como evidenciado na resposta da educadora C, a formação contribuiu para que entendesse melhor o estudante e é a partir desse entendimento que acreditamos ser possível ocorrer a interlocução entre educador e educando, necessária para uma educação dialética, e assim nossa inquietação nos permite ainda problematizar, como está o processo educativo em contextos campesinos em que não se discute a diversidade, a interculturalidade, em que se oferta aos educadores palestras e formações empacotadas? Questão que nos acompanhará temporariamente sem resposta, mas que buscaremos responder em outro momento.

Mas, a formação continuada em questão, enquanto processo formativo que provoca reflexões e compreensão nos permite dizer que, possibilita ao educador propor leituras, e escritas significativas, que ao entender que nesse movimento em que ensina e aprenda FREIRE ( 1997), é capaz de ouvir e transformar com os educandos os saberes desses sujeitos em conhecimento, mostrando-se como educador ativo, reflexivo e crítico de sua prática, numa ação dialética.

Fazemos um destaque também as respostas das educadoras $B$ e $D$ sobre a motivação pela realização de projetos voltados para a Educação do Campo e a troca de experiências que ocorre nesse processo formativo têm impulsionado o fazer diferente, a busca por experiências e práticas que tenham sentido/significado para os educandos, propiciando reflexões sobre a teoria e a prática. 


\section{Considerações finais}

A pesquisa nos permitiu constatar que as práticas instituídas na escola têm demonstrado um esforço em tornar o processo ensino aprendizagem significativo para os educandos, não apenas no que se refere a produção escrita, mas em todas as disciplinas que tivemos a oportunidade de acompanhar $e$ observar. Revelou tanto o desejo de fazer diferente por parte das educadoras, como a dúvida, se fazendo presente no recuo das práticas diferenciadas quando o sistema, a disciplina, o currículo nos parece uma imposição. Paradigma que tem aprisionado os profissionais da educação, que mesmo reconhecendo a importância e a necessidade da mudança, da inovação, recuam, pois precisam cumprir o conteúdo ou mesmo terminar o livro didático.

Registramos que, ao evidenciarmos uma escola do campo e refletirmos sobre o que é proposto aos educandos como possibilidade de produção escrita, defendemos que se considere a realidade e as vivências desses sujeitos, para se propor um debate, uma leitura, uma escrita. Mais importante ainda, é que podemos transpor essas considerações para qualquer espaço tempo escolar, ou seja, considerar o contexto em que a escola está inserida e os educandos que nela estão, com a intenção de superarmos uma educação dicotômica, que distingue o campo da cidade, a escola pública da particular, os grandes centros da periferia e tantas outras classificações que não substanciam a nossa intenção nesta pesquisa.

O Projeto Integrando Saberes que, em sua essência, tem por base os temas geradores fundamentados em Freire (2013), demonstra a possibilidade de ouvir os diversos saberes, relacionando-os com as vivências e necessidades sentidas dos educandos, conseguido fazer com que eles escrevam, produzam seus textos, produções essas que revelam as práticas escolares, influenciadas pelos modelos de produção textual mais valorizados pela tradição escolar, mas que, apesar disso, têm conseguido, aos poucos, fazer com o que o estudante diga a sua palavra e sinta-se capaz disso.

A pesquisa constata que as produções escritas têm se pautado, principalmente, em narrativas e relatórios descritivos. Geraldi (2010) destaca a 
preferência da escola por textos pragmáticos e referenciais em detrimento da produção literária e, assim, outras leituras e produções deixam de ser realizadas, aprendidas, vividas. Diante disso, mais uma vez, a escola encontra-se enredada pelo sistema, pelo currículo dominante, que prima pelos autores escritores, ou mesmo, reprodutores em detrimento dos autores criativos e críticos. Autores esses, que estão dispostos ao novo, que têm sua opinião e vontade de escrever, mas que necessitam de motivação, estímulo e atenção às suas necessidades.

Enquanto a escola, na figura dos educadores que têm o potencial de transformar a educação num movimento de libertação e emancipação dos sujeitos, não perceber os mecanismos que a amarram, que buscam domesticála, sendo para isso necessário um processo de catarse, de rompimento e transformação das estruturas, ou seja , de superação do sistema educacional "imposto", continuará a atender não aqueles que a procuram com sede de saber e esperança, e sim aqueles que desejam que as coisas permaneçam como estão, e para que isso ocorra, ler e escrever bem não representam uma prioridade.

\section{Referências}

ALTHUSSER, L. Aparelhos Ideológicos do Estado. Rio de Janeiro: Edições Graal, 1985.

ARROYO, Miguel G. Políticas de Formação de Educadores (as) do campo. Cad. Cedes, Campinas, vol.27, n.72, p. 157-176, maio/ago. 2007 Disponível em <http://www.cedes.unicamp.br acesso em 17 de junho de 2014.

. Currículo, território em disputa. 5. ed. Petrópolis: Vozes, 2013.

BAGNO, Marcos. Preconceito linguístico: o que é, como se faz. 52 ed. São Paulo: Loyola, 2009.

BAKHTIN, Mikhail. Marxismo e Filosofia da Linguagem. 14 ed. São Paulo: Editora Hucitec, 2010a. 2010b.

Estética da Criação Verbal. 5 ed. São Paulo: Editora MartinsFontes,

BRASIL. Ministério da Educação. Lei no 9.394 de 20 de Dezembro de 1996.

Estabelece as Diretrizes e Bases da Educação Nacional - LDB. Brasília, dez. 1996. 
Ministério da Educação. Conselho Nacional

deEducação.ParecerCNE/CEB No 36/2001. Diretrizes Operacionais para a Educação Básica nas Escolas do Campo.Brasília:MEC/CNE,2002.

.Resolução CNE/CEB $\mathrm{n}^{\circ}$ 01/2001. Diretrizes Operacionais para aEducação Básica nas Escolas do Campo. Brasília: MEC/CNE,2002.

Comitê Nacional de Educação em Direitos Humanos. Plano Nacional de Educação em Direitos Humanos: 2007. Brasília: Secretaria Especial dos Direitos Humanos, 2003 e 2007. Disponível em:

<http://www.mj.gov.br/sedh/edh/pnedhpor.pdf>. Acesso em: 25 abr. 2015.

de Resolução CNE/CEB, $n^{\circ}$ 2/2008. Diretrizes Complementares, Normas e Princípios para o Desenvolvimento de Políticas Públicas de Atendimento da Educação Básica do Campo. Brasilia: MEC/CNE,2008.

. Ministério da Educação. Lei no 13005 de 25 de junho de 2014.Plano Nacional de Educação: 2011-2020. Brasília,2014.

CALDART, R. S. Por Uma Educação do Campo: traços de uma identidade em construção. In: KOLLING, E. J.; CERIOLI, P. R.; CALDART, R. S. Por Uma

Educação do Campo: Identidade e Políticas Públicas. Articulação Nacional Por uma educação do campo n. 4. p. 25 - 36. Brasília, 2002.

.Elementos para Construção de um Projeto Político e Pedagógico da Educação do Campo. In: MOLINA, M. C. e JESUS, S. M. A. de. Por uma Educação do Campo: Contribuições para construção de um Projeto de Educação do Campo. Articulação Nacional Por uma educação do campo n. 5, p. $10-31.2004$.

CALIARI, Rogério O. A prática pedagógica da formação continuada. In: MERLER, Alberto (ORGs.) Et al. Educação do Campo: diálogos interculturais em Terras Capixabas. Vitória: Edufes, 2013.

A presença da família camponesa na escola família agrícola :o caso de Olivânia. Dissertação (Mestrado em Educação) - Programa de PósGraduação em Educação, Universidade Federal do Espírito Santo, Vitória,2013.

CANDAU, Vera M. F. A formação continuada de professores: tendências atuais. In: REALI, Aline de M. R. MIZUKAMI M. da G. N. (orgs.) Formação de professores: tendências atuais: São Carlos: EDUFSCar, 1996. p.139-152.

Diferenças culturais, interculturalidade e educação em direitos humanos. Educ. Soc., Campinas, v. 33, n. 118, p. 235-250, jan.-mar. 2012 disponível em: http://www.scielo.br/pdf/es/v33n118/v33n118a15.pdf. Acesso em: 01 jun.2014.

Diferenças culturais, cotidiano escolar e práticas pedagógicas. Currículo sem Fronteiras, v.11, n.2, pp.240-255, Jul/Dez 2011 
disponível em: http://.curriculosemfronteira.org/vol11iss2articles/candau.pdf. Acesso em: 01 jun.2014.

CAPES, Banco de Teses Capes. http://bancodeteses.capes.gov.br/. Acesso em: maio, junho e julho de 2014.

CORREAA, Tânia R. S. G. Os reflexos do SAEB/Prova Brasil nas práticas pedagógicas de Língua Portuguesa nas escolas municipais de Costa Rica/MS. Dissertação(Mestrado em Educação) - Programa de Pós-Graduação em Educação, Universidade Católica Dom Bosco, Campo Grande/MS, 2012.

DEMENECH, Flaviane; DICKEL, Adriana. Cultura escolar e cultura da escola: Produção e reprodução a partir dos fatores intraescolares. Revista Professare, ISSN 2238-9172, Caçador, v.5, n. 2, p.21-42, 2016.

FERNANDES, B. M.; MOLINA, M. C. O campo da Educação do Campo. In: MOLINA, M. C.; JESUS, S. M. S. A. De (Orgs.) Contribuições para a construção de um Projeto de Educação do Campo. Articulação Nacional —Por uma Educação do Campoll, n. 5, Brasília, 2004.

FOERSTE, Erineu. Parceria na formação de professores. São Paulo: Cortez, 2005.

FOERSTE, Erineu; CHÜTZ-FOERSTE, Gerda M.; CALIARE, Rogério. Introdução à Educação do Campo. Vitória, ES: UFES, Programa de Pós Graduação em Educação, 2009.

FREIRE, Paulo. A importância do ato de ler: em três artigos que se completam, 50 ed.São Paulo: Cortez, 2009. 1994.

Educação como prática da liberdade. Rio de Janeiro: PazeTerra,

Pedagogia do oprimido. 54 ed. Rio de Janeiro: Paz e Terra,2013.

GERALDI, João W. A aula como acontecimento. São Carlos: Pedro \& João Editores, 2010.

. Portos de Passagem. 5 ed. São Paulo: WMF Martins Fontes,2013.

. (org.) O texto na sala de aula. 3 ed. São Paulo: Ática.1999.

GERKE DE JESUS, Janinha. Saberes e formação de professores na pedagogia da Alternância. Vitória: Programa de Pós-Graduação em Educação/UFES, 2006.

JESUS, Janinha G. de; Foerste, Erineu. Educação do Campo no Brasil: uma aproximação. Disponível em: <http://www.ufes.br/educacaodocampo/down/cdrom/>. Acesso em: 17dez. 2013. 
LOPES, Andreia de M. L. O capital cultural da criança na aprendizagem da linguagem escrita. Dissertação(Mestrado em Educação) - Programa de PósGraduação em Educação, Universidade de Passo Fundo, Rio Grande do Sul, 2011. LÜDKE, M; ANDRÉ. M. E. D. A. Pesquisa em educação: abordagens qualitativas. São Paulo: EPU, 1986.

RODRIGUES, Jéssica do N.; RANGEL, Mary. A prática de professores da Língua Materna no Ensino Fundamental da Baixada Fluminense (RJ): a produção textual escrita e avaliação. In. REUNIÃO ANUAL DA ASSOCIAÇÃO NACIONAL DE PÓS-GRADUAÇÃO E PESQUISA EM EDUCAÇÃO, Anais eletrônicos. Disponível: <http://36reuniao.anped.org.br/pdfs_trabalhos_aprovados/gt10_trabal>.

Acesso: 28 out. 2014.

Secretaria Municipal de Educação e Esporte de Domingos Martins. Índices de evasão e reprovação,2010.

SILVA, Tomaz Tadeu da.Documentos de identidade: uma introdução às teorias do currículo. $2^{a}$ ed. Belo Horizonte: Autêntica, 2002.

SOARES, M. Letramento: um tema em três gêneros. Belo Horizonte: Autêntica,1998.

SOUSA, S. Z.; ARCAS, P.H. Implicações da Avaliação em Larga Escala no Currículo: revelações de escolas estaduais de São Paulo, 2010. Disponível emhttp://www.periodicos.rc.biblioteca.unesp.br/index.php/educacao/article/view File/4 091/3298.

TARDIF, Maurice. Saberes Docentes e Formação Profissional. Petrópolis: Vozes, 2002.

THIES, Vânia G.; PERES, Eliane T. Quando a escrita ressignifica a vida: diários de um agricultor- uma prática de escrita masculina. In: REUNIÃO ANUAL DA ASSOCIAÇÃO NACIONAL DE PÓS-GRADUAÇÃO E PESQUISA EM EDUCAÇÃO, Anaiseletrônicos... Disponível em: <http://31reuniao.anped.org.br/1trabalho/GT10- 4050--Int.pdf>. Acesso em: 16 out. 2014.

VIGOTSKI, Lev S. Pensamento e Linguagem. São Paulo: Martins Fontes, 1996.

\section{Sobre os autores}

\section{Roseli Gonoring Hehr}

rosegonoring@gmail.com

Doutoranda e Mestre em Educação pelo Programa de Pós-graduação em Educação da UFES. Especialização em Educação do Campo: Interculturalidade e Campesinato em Processo Educativos pela UFES. Graduada em Pedagogia pela UFES e Licenciada em Letras pela Faculdade de Filosofia, Ciências e Letras 
de Colatina. Membro do Grupo de Pesquisa(CNPq) Culturas, Parcerias e Educação do Campo. Professora dos anos iniciais e finais da Prefeitura de Vitória- ES. Gerente Técnico-Pedagógica da Secretaria Municipal de Educação e Esporte de Domingos Martins.

\section{Erineu Foerste}

erineu.foerste@ufes.br

Professor Associado da Universidade Federal do Espírito Santo. Membro do colegiado do Programa de Pós-Graduação em Educação. Fundador e líder do Grupo de Pesquisa (CNPq) Culturas, Parcerias e Educação do Campo. 